\title{
Use of an improved cetrimide agar medium and other culture methods for Pseudomonas aeruginosa
}

\author{
V. I. BROWN AND E. J. L. LOWBURY \\ From the M.R.C. Industrial Injuries and Burns Research Unit, \\ Birmingham Accident Hospital
}

SYNOPSIS In a comparison of two selective media for Ps. aeruginosa containing $0.03 \%$ cetrimide, $\vec{\infty}$ stronger fluorescence was obtained from growth on the medium prepared with King's medium B as the base (CTA 2); although Ps. aeruginosa was not isolated more frequently from burns on this medium than from cetrimide agar made with a Lemco base (CTA 1), results were easier to assess음 and there were fewer cases of doubtful fluorescence on CTA 2 than on CTA 1.

Pyocyanin production on CTA 1 was better than on CTA 2, but for demonstration of pyocyanin $Z$ production Wahba and Darrell's medium was preferable and showed the pigment in $455 / 497(92 \%) \underset{\Phi}{7}$ of fluorescent strains of Ps. aeruginosa from burns.

A series of tests on 99 strains of Ps. aeruginosa or presumptive Ps. aeruginosa, on 30 strains of other species of Pseudomonas, and on 68 strains of other species of Gram-negative rods showed the $\vec{\odot}$ value of growth on cetrimide agar and on triphenyl tetrazolium chloride medium, of slime production $v$ in gluconate broth, of gas production from nitrate, and of growth at $42^{\circ} \mathrm{C}$. as diagnostic aids in the recognition of Ps. aeruginosa.

A selective medium containing $0.03 \%$ cetrimide in Lemco agar (Lowbury and Collins, 1955) has for many years been used here and found effective in the isolation of Pseudomonas aeruginosa (Ps. pyocyanea) from burns and other sources; with the aid of ultraviolet irradiation, fluorescin is easily detected in the majority of cultures of Ps. aeruginosa on this medium and on certain other solid media (Lowbury, 1951; Lowbury, Lilly, and Wilkins, 1963). Many fluorescent cultures also show the presence of pyocyanin by varying degrees of blue-green pigmentation. A few strains of Ps. aeruginosa show relatively poor fluorescence, and non-fluorescent strains, which are in other respects indistinguishable from $P s$. aeruginosa, are very occasionally isolated.

King, Ward, and Raney (1954) have described two media, one of which (medium A) enhances the production of pyocyanin by $P$ s. aeruginosa, while the other (medium B) enhances the production of fluorescin. An improved medium for pyocyanin production (modified Sierra medium) has been developed by Wahba and Darrell (1965). In this paper we describe the improvement of cetrimide agar by the use of King's medium B as the base; we compare the frequency of isolation of Ps. aeruginosa from natural sources (burns) on the new and the Received for publication 1 June 1965. old cetrimide agar, and also assess the value of $\frac{\mathscr{Q}}{\varnothing}$

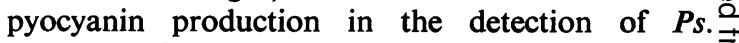
aeruginosa from the same sources. A comparison of 99 strains of $P$ s. aeruginosa and presumptive $P$ s. aeruginosa with other pseudomonads and species of Gram-negative rods is described.

\section{MATERIALS AND METHODS}

CULTURE MEDIA Two cetrimide agar media were prepared.

Cetrimide agar with Lemco base (CTA 1) This was a slightly modified form of the medium described by Lowbury and Collins (1955) and contained the following ingredients:-Peptone (Oxoid), $10 \mathrm{~g}$.; Lab-Lemco (beefextract), 10 g.; sodium chloride, 5 g.; agar (New Zealand), N $15 \mathrm{~g}$.; distilled water, $1,000 \mathrm{ml}$. The $p \mathrm{H}$ was adjusted to 7.4. This basal medium was autoclaved at $121^{\circ} \mathrm{C}$. for $\mathrm{N}$ 15 minutes and stored. To prepare the selective medium ${ }_{\mathrm{W}}$ it was melted in the steamer and cooled to $45^{\circ} \mathrm{C} . ; 15 \mathrm{ml} .0$ of a Seitz-filtered $2 \%$ solution of cetrimide (B.P.) was then added, to give a concentration of $0.03 \%$ in the medium.

Cetrimide agar with modified King's base (CTA 2) The? basal medium was prepared as follows:-Proteose $\frac{T}{T}$ peptone no. 3 (Difco), 20 g.; New Zealand agar, 15 g.; glycerol, $10 \mathrm{~g}$.; distilled water, $1,000 \mathrm{ml}$. The medium was adjusted to $p H \mathbf{H} 7$. It was autoclaved for 15 minutes at $\vec{\Phi}$ $121^{\circ} \mathrm{C}$. and stored. To $100 \mathrm{ml}$. of the melted solution were 
added $1 \mathrm{ml}$. of a $15 \%$ solution of $\mathrm{K}_{2} \mathrm{HPO} 4$ (anhydrous) and $1 \mathrm{ml}$. of a $15 \%$ solution of $\mathrm{MgSO} 47 \mathrm{H}_{2} \mathrm{O}$; these solutions were prepared with distilled water and sterilized by Seitz filtration. A Seitz-filtered $2 \%$ solution of cetrimide (B.P.) was added to the basal medium to give a final concentration of $0.03 \%$ cetrimide for the selective medium.

Wahba and Darrell's (1965) modified Sierra medium for enhancement of pyocyanin production (P.A.) was prepared as follows (Wahba, personal communication):Bacto peptone (Difco), $10 \mathrm{~g}$.; $\mathrm{NaCl}, 5 \mathrm{~g}$.; $\mathrm{CaCl}_{2} \mathbf{1 H}_{2} \mathrm{O}$, $0.1 \mathrm{~g}$.; agar (Davis), $18.0 \mathrm{~g} . ;$ water (distilled), 1,000 ml.

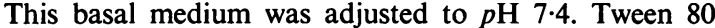
and $\mathrm{MgSO} 47 \mathrm{H}_{2} \mathrm{O}$ solutions were separately autoclaved and added to the basal medium to give a final concentration of $1.0 \%$ and $0.1 \%$ respectively.

EXPERIMENTS 1 A comparison was made of cetrimide agar with Lemco base (CTA 1) and cetrimide agar with a slightly modified King's base (CTA 2) in the isolation of $P s$. aeruginosa from 1,780 consecutive swabs from burns. The swabs were taken and set up in culture as described elsewhere (Lowbury, 1960). For the comparison of cetrimide media, subcultures were plated on to them from cooked meat broth cultures which had been incubated at $37^{\circ} \mathrm{C}$. overnight. Plates of cetrimide agar were inoculated by transferring a loopful of each liquid culture to a marked square on the solid medium ('spot plate'); up to 25 cultures could be inoculated on one spot plate.

Cultures were examined after approximately 18 and 42 hours' incubation at $37^{\circ} \mathrm{C}$. for growth on the selective medium and for pigment production; they were also examined for characteristic fluorescence under ultraviolet irradiation in a viewing cabinet (Lowbury et al., 1963). Growth on cetrimide agar with production of characteristic fluorescence was taken as presumptive evidence that the culture contained Ps. aeruginosa.

All cultures were also inoculated on spot plates of Wahba and Darrell's medium for pyocyanin production, six strains per plate; cultures showing poor or doubtful blue pigment production after $\mathbf{4 8}$ hours' incubation were inoculated on slopes of Wahba and Darrell's medium and were extracted after 48 hour's incubation by grinding the medium with a small volume of chloroform; the separated layer of chloroform was examined for blue pigment.

2 A comparison was made of CTA 1, CTA 2, and PA medium in the isolation of Ps. aeruginosa by direct inoculation of material from selected burn swabs. Swabs taken from burns were extracted first by rubbing thoroughly in a small volume $(0.2 \mathrm{ml}$.) of nutrient broth. These extracts were inoculated by wire loop on spot plates of CTA 1 and CTA 2 and on slopes of Wahba and Darrell's medium (PA). Cultures on CTA 1 and CTA 2 were examined as described above; cultures on PA were examined after 48 hours' incubation at $37^{\circ} \mathrm{C}$. for blue pigment; a proportion of these tubes showing varying degrees of blue pigmentation or non-detectable pigment were extracted with chloroform and examined for chloroform-soluble pigment.

3 A series of tests was made on 99 strains of presumptive $P$ s. aeruginosa (so described on the basis of character- istic growth and fluorescence on $0.03 \%$ cetrimide agar), 55 strains of known genera or species of other Gramnegative rods, and 30 strains of known species of Pseudomonas. The tests were as follows:-(1) Morphology (Gram stain); (2) growth on cetrimide agar (CTA 1); (3) fluorescence on CTA 1 ; (4) pyocyanin production (on Wahba and Darrell's medium); (5) oxidase production (Kovacs, 1956); (6) nitrate reduction with production of gas, by the Griess-Ilosvay method (Wilson and Miles, 1964); (7) growth at $42^{\circ} \mathrm{C}$. in nutrient broth; (8) deamidation of acetamide (Bühlmann, Vischer, and Bruhin, 1961); (9) glucose oxidation/fermentation (Hugh and Leifson, 1953); (10) arginine dihydrolase (Thornley, 1960); (11) gelatin liquefaction (in nutrient gelatin stabs, examined after 24 hours' incubation at $37^{\circ} \mathrm{C}$.); (12) egg yolk reaction (Klinge, 1960); (13) gluconate oxidation and slime production (Haynes, 1951); a loopful of an overnight broth culture was inoculated into a medium prepared for the gluconate oxidation test (Cruickshank, 1965). The test for slime production was made by touching the top of the culture with a wire loop and drawing the loop back to the mouth of the tube; slime was shown by the presence of a mucoid 'string'; and (14) growth in triphenyl tetrazolium chloride medium (Selenka, 1958).

\section{RESULTS}

Table I shows a comparison of the two cetrimide agar media for the isolation of Ps. aeruginosa from cooked meat broth cultures of burn swabs. When $P s$. aeruginosa was isolated it appeared on both media, but in all except 12 cultures fluorescence was stronger on the medium made with King's base (CTA 2). The medium made with Lemco base, on the other hand, showed better pyocyanin production; growth on CTA 2 had a vivid lemon-yellow colour, while that on CTA 1 was often dark or bluish green, and the presence of pyocyanin reduced the intensity of fluorescence under ultraviolet irradiation.

\section{TABLE I}

ISOLATION OF PSEUDOMONAS AERUGINOSA FROM BURNS ON TWO CETRIMIDE AGAR MEDIA

\begin{tabular}{lc} 
Tests & $\begin{array}{c}\text { Results (Number } \\
\text { of Swabs) }\end{array}$ \\
\hline Total swabs & 1,780 \\
Ps. aeruginosa isolated & \\
CTA 1 and CTA 2 & 497 \\
CTA 1 only & 0 \\
CTA 2 only & 0 \\
Fluorescence under ultra-violet light & \\
Stronger on CTA 2 & 485 \\
Stronger on CTA 1 & 0 \\
Equal to CTA 1 and CTA 2 & 12 \\
Doubtful fluorescence & \\
On CTA 1 & \\
On CTA 2 & 4 \\
Pyocyanin in PA medium & 0 \\
\end{tabular}


Of the 497 strains of fluorescent pseudomonas isolated in these cultures, $455(92 \%)$ showed blue pigment in Wahba and Darrell's medium. Although it was often possible to recognize pyocyanin production in CTA 1, many strains which showed good pigmentation in Wahba and Darrell's medium did not show obvious blue-green or dark green pigment on CTA 1. Pyocyanin was not seen in cultures on PA from any specimen which did not show fluorescent growth on CTA 1 or CTA 2.

Table II shows the results of parallel culture of 158 selected swabs from burns on CTA 1, CTA 2, and PA media. From 84 of these Ps. aeruginosa was isolated on solid medium; the majority of these (54) showed Ps. aeruginosa on all three media, but from eight specimens the organism was detected only on one medium, and from 22 it was detected only on two of the media. Although fluorescence was almost always better on CTA 2 than on CTA 1, there were seven specimens which showed fluorescent growth on CTA 1 but not on CTA 2; and although fluorescin production was shown in subculture from liquid medium to be a more general property of these strains than pyocyanin production (see Table I), on direct inoculation four specimens were detected by pyocyanin production when fluorescin production was not detected, in each case a mixed growth of Ps. aeruginosa and of a Proteus which was able to grow on CTA 1.

\section{TABLE II}

ISOLATION OF PSEUDOMONAS AERUGINOSA ON TWO CETRIMIDE AGAR MEDIA AND ON A MEDIUM FOR PYOCYANIN PRODUCTION (PA) BY DIRECT INOCULATION OF SWAB EXTRACTS

Tests
$\begin{aligned} & \text { Results (Number } \\ & \text { of Swabs) }\end{aligned}$

Ps. aeruginosa isolated on direct inoculation of solid media

Ps. aeruginosa isolated:

On CTA 1, CTA 2, and PA

Only on CTA 1

Only on CTA 2

Only on PA

Only on CTA 1 and CTA 2

Only on CTA 1 and PA

Only on CTA 2 and PA

Table III shows the results of examining 99 strains of Ps. aeruginosa or presumptive Ps. aeruginosa, 30 strains of other pseudomonads, and 68 strains of other genera and species of aerobic Gram-negative rods for growth on CTA 1. Plates were inoculated with loopfuls of undiluted 24-hour broth cultures; they were incubated at approximately $22^{\circ} \mathrm{C}$. when the strains had been shown in previous tests to grow poorly at $37^{\circ} \mathrm{C}$. on blood agar; those which grew
TABLE III

GROWTH OF PSEUDOMONAS AERUGINOSA AND OTHER GRAM-NEGATIVE RODS ON CETRIMIDE AGAR (CTA 1)

\begin{tabular}{|c|c|c|c|c|c|c|c|c|c|}
\hline \multirow{2}{*}{$\begin{array}{l}\text { Temperature of } \\
\text { Incubation }^{1}\end{array}$} & \multicolumn{3}{|c|}{$\begin{array}{l}\text { Growth of Ps. } \\
\text { aeruginosa or } \\
\text { Presumptive } \\
\text { Ps. aeruginosa }\end{array}$} & \multicolumn{3}{|c|}{$\begin{array}{l}\text { Growth of } \\
\text { Other Pseudo- } \\
\text { monads }\end{array}$} & \multicolumn{2}{|c|}{$\begin{array}{l}\text { Growth of } \\
\text { Other Gram- } \\
\text { negative Rods }\end{array}$} & \\
\hline & & $+o r \pm$ & - & ++ & $+o r \pm$ & - & ++ & $+o r \pm$ & \\
\hline & 99 & 0 & 0 & 0 & 2 & & 0 & & \\
\hline otal & $\overline{99}$ & $\overline{0}$ & $\overline{0}$ & $\begin{array}{l}1^{2} \\
1\end{array}$ & $\begin{array}{l}18 \\
20\end{array}$ & $\begin{array}{l}5 \\
9\end{array}$ & $\begin{array}{l}\mathbf{0} \\
0\end{array}$ & $\begin{array}{r}0 \\
26\end{array}$ & \\
\hline
\end{tabular}

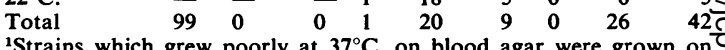
CTA 1 at approximately $22^{\circ} \mathrm{C}$. (room temperature); other strains $\vec{\infty}$ were grown at $37^{\circ} \mathrm{C}$.

${ }^{2} P s$, putida

${ }^{3}++=$ heavy growth $+=$ moderate growth; $t=$ scanty g owth

$+t$ heavy growth; $t=$ moderate growth; \pm scanty growth

well on blood agar at $37^{\circ} \mathrm{C}$. were grown on CTA 1 at $^{\circ}$ $37^{\circ} \mathrm{C}$. The following strains of pseudomonas were tested:-Ps. aeruginosa (96), Ps. aeruginosa varo pyorubin (2), Ps. polycolor (grouped here with Ps. $\frac{\Phi}{7}$ aeruginosa) (1), Ps. fluorescens (8), Ps. putida (1), ठ Ps. marginalis (1), Ps. pastinaceae (1), Ps. viridiflava (1), Ps. syringae (2), Ps. ovalis (1), Ps. astrofaciens (1), $\vec{\bullet}$ Ps. fragi (1), Ps. denitrificans (1), Ps. oxidans (5), G Ps. alcaligenes (1) and Ps. species (3). Of the otherGram-negative rods the following were tested:\& Proteus mirabilis (16), Providence (Proteus inconstans) (5), Escherichia coli (9), Enterobacter aerogenes (6), Klebsiella aerogenes (1), Cloaca sp. (11), Achromo-市 bacter anitratus (7), Alcaligenes sp. (7), and Coma monas sp. (6).

All the strains of Ps. aeruginosa showed a heavy growth after 18 hours' incubation on CTA 1 . Of the other strains of pseudomonas, only Ps. putida grew heavily on the selective medium, but this and mosto of the other strains of pseudomonas did not grow well at $37^{\circ} \mathrm{C}$. and were tested at $22^{\circ} \mathrm{C}$. Most of the other species of Gram-negative rods failed to growo on CTA 1 , and none gave a heavy growth on CTA 1, though moderate or scanty growth was obtainedo from 12 strains of Proteus mirabilis, five strains of Providence (Proteus inconstans), and two strains of? Comamonas. When no growth was found after $18 \mathrm{n}$ hours, plates were reincubated for six days and? re-examined.

Table IV shows the results of examining these strains by a number of tests which have been foundo useful in the study of Pseudomonas species. Moste strains of presumptive $P$ s. aeruginosa showed severa features which usually differentiated them and other pseudomonads from the majority of other Gram-0 negative rods (oxidase reaction, oxidative metabolism of glucose, positive arginine dihydrolase reaction $\Omega$ and acetamide deamidation); they also showed certain $\frac{1}{2}$ features which differentiated them from most othero 
TABLE IV

MISCELLANEOUS TESTS ON PS. AERUGINOSA AND OTHER GRAM-NEGATIVE RODS

\begin{tabular}{|c|c|c|c|}
\hline Test & $\begin{array}{l}\text { Ps. } \\
\text { aeruginosa } \\
\text { or Pre- } \\
\text { sumptive } \\
\text { aeruginosa }\end{array}$ & $\begin{array}{l}\text { Other } \\
\text { Pseudomonads }\end{array}$ & $\begin{array}{l}\text { Other Gram- } \\
\text { negative Rods }\end{array}$ \\
\hline & + & - & + \\
\hline
\end{tabular}

\begin{tabular}{lllllll}
\hline Fluorescence on CTA 1 & 98 & 1 & 9 & 21 & 0 & 68
\end{tabular}

Pyocyanin production

(on Wahba and

$\begin{array}{lrrrccc}\text { Darrell's medium) } & 87 & 12 & 0 & 30 & 0 & 68 \\ \text { Oxidase (Kovacs) } & 99 & 0 & 28 & 2^{2} & 13^{3} & 55\end{array}$

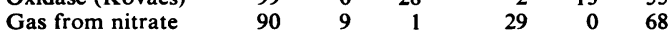

$\begin{array}{lllllll}\text { Growth at } 42^{\circ} \mathrm{C} . & 98 & 1 & 5 & 25 & 59 & 9\end{array}$

$\begin{array}{llllll}\text { Acetamide deamidation } 98 & 1 & 17 & 13 & 5^{4} & 63\end{array}$

$\begin{array}{llllll}\text { Hugh and Leifson's test } 99 & 0 & 29 & 1 & 19^{5} & 49\end{array}$

$\begin{array}{lllllll}\text { Arginine dihydrolase } & 99 & 0 & 24 & 6 & 14^{6} & 54\end{array}$

$\begin{array}{lllllll}\text { Gelatin liquefaction } & 90 & 9 & 11 & 19 & 26 & 42\end{array}$

$\begin{array}{lrlll}\text { Egg yolk reaction } & 8( \pm) 91 & 11 & 19 & 6( \pm) 62\end{array}$

$\begin{array}{lllllll}\text { Gluconate oxidation } & 95 & 5 & 17 & 13 & 11 & 57\end{array}$

$\begin{array}{lllllll}\text { Slime production } & 98 & 1^{5} & 0 & 30 & 0 & 68\end{array}$

$\begin{array}{lllllll}\text { Growth in triphenyl } & & & & & & \\ \text { tetrazolium chloride } & 97 & 2 & 7(4= \pm) & 23 & 6^{7} & 62\end{array}$

${ }^{1}$ Gram-negative rods growing and giving characteristic yellow, green,

or blue green fluorescence on CTA 1 or CTA 2 at $37^{\circ} \mathrm{C}$.; atypical

strains showing purple fluorescence are also included.

${ }^{2}$ Ps. syringae

${ }^{3}$ Six Comamonas and seven Alcaligenes.

"Providence.

${ }^{5}$ Seven $A$. anitratus, six Comamonas ( \pm ), and six Alcaligenes ( \pm ).

'Eleven Cloaca and three $E$. coli.

${ }^{7}$ Cloaca.

${ }^{8} \mathrm{~A}$ strain which produced no pyocyanin or fluorescin, but showed atypical purple fluorescence; gluconate oxidation, growth on tetrazolium chloride medium, and gelatin liquefaction were negative, but their reactions were characteristic of Ps. aeruginosa.

pseudomonads as well (slime production, pyocyanin production, and production of gas from nitrate), or from other pseudomonads though not from some of the Enterobacteriaceae (growth at $42^{\circ} \mathrm{C}$.).

Slime was present in gluconate broth cultures of all but one of the strains of Ps. aeruginosa (or presumptive Ps. aeruginosa) and not found in growth of any of the other pseudomonads or other Gram-negative rods. The test was of interest both on account of its diagnostic value and because of the probable importance of slime as a factor in the pathogenicity of Ps. aeruginosa (Liu, Abe, and Bates, 1961).

All but one of the strains of Ps. aeruginosa (a pyorubin producer) showed fluorescent pigment on CTA 1 and CTA 2; five of these strains showed an atypical purple fluorescence which has been found in extremely few of the thousands of strains seen in the routine examination of the laboratory.

\section{DISCUSSION}

In these studies Ps. aeruginosa usually fluoresced much more brilliantly on cetrimide agar made with King's base (CTA 2) than on Lemco-based cetrimide agar (CTA 1) (Lowbury and Collins, 1955); although pyocyanin, a pigment produced only by $P$ s. aeruginosa, was more abundant in growth on CTA 1 than on CTA 2, this advantage was outweighed by the better production on CTA 2 of fluorescin, a pigment produced by a larger proportion of strains of $P s$. aeruginosa (virtually all). If the hands of those familiar with both media, Ps. aeruginosa was isolated as often on CTA 1 as on CTA 2, but those with less experience of CTA 1 might have been in doubt about some of the strains showing weaker fluorescence on this medium. It detection of both fluorescin and pyocyanin is desired, special media should be used for each pigment. For fluorescin, King's medium B (King et al., 1954) is highly effective, and can be converted into a selective medium by inclusion of $0.03 \%$ cetrimide. Wahba and Darrell's (1965) medium is equally effective for the detection of pyocyanin; the presence of Tween 80 in this medium, however, makes it incompatible with the selective agent, cetrimide. Blue pigment can be found in the medium even when Ps. aeruginosa is heavily outnumbered by other bacteria (occasional strains of which may grow moderately well on CTA media and prevent the recognition of fluorescent pigment).

Attempts to improve the fluorescence under ultra-violet irradiation of Ps. aeruginosa on blood agar by using King's base and some modifications of it were fairly successful, but the colonial appearance of various other bacteria, including Staphylococcus aureus, was less recognizable than on standard blood agar media. The method was therefore not considered practicable and no further investigation was made of its use.

A range of tests on many strains of presumptive Ps. aeruginosa, i.e., Gram-negative rods growing and fluorescing on cetrimide agar, and of other known species of Pseudomonas, Klebsiella, Escherichia, Proteus, Enterobacter, and other Gram-negative rods has confirmed the value of growth on cetrimide agar and detection of fluorescence in the recognition of Ps. aeruginosa isolated from clinical material. A few other pseudomonads (Ps. fluorescens, Ps. putida, Ps. marginalis, Ps. pastinaceae, Ps. astrofaciens) also gave fluorescent growth on CTA media at $22^{\circ} \mathrm{C}$., but grew poorly, if at all, at $37^{\circ} \mathrm{C}$., and failed to grow at $42^{\circ} \mathrm{C}$.; Ps. aeruginosa could be differentiated from them by other tests (notably slime production in virtually all and pyocyanin production in most of the strains tested).

Studies with electronic computers have shown that the species Ps. aeruginosa forms a fairly well defined 'taxonomic cluster' (Colwell and Liston, 1961; Colwell, 1964). In this study we have not attempted to match our strains with the median Ps. aeruginosa defined by computer analysis, but have examined 
these strains with a small series of tests that have particular value in differentiating Ps. aeruginosa; from this we were able to assess the value and limitations of fluorescent growth on cetrimide agar as a presumptive test and showed which additional tests are desirable for confirmation and for improvement of diagnosis of Ps. aeruginosa.

We are grateful to Dr. Eve Billing, Dr. K. P. Carpenter, Dr. R. G. Mitchell, Dr. R. W. A. Park, Dr. M. E. Rhodes, Dr. A. H. Wahba, and the National Collection of Type Cultures for kindly supplying us with strains of pseudomonas. We also wish to thank Dr. Billing and Dr. Wahba for valuable suggestions.

\section{REFERENCES}

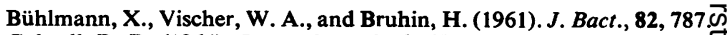
Colwell, R. R. (1964). J. gen. Microbiol., 37, 181.

, and Liston, J. (1961). J. Bact., 82, 1.
Cruickshank, R. (1965). Medical Microbiology. A Guide to the Laboratory Diagnosis and Control of Infection, 11 th ed., p. $831 \overline{\bar{c}}$ Livingstone, Edinburgh.

Haynes, W. C. (1951). J. gen. Microbiol., 5, 939.

Hugh, R., and Leifson, E. (1953). J. Bact., 66, 24.

King, E. O., Ward, M. K., and Raney, D. E. (1954). J. Lab. clin. med. @ $44,301$.

Klinge, K. (1960). J. appl. Bact., 23, 442.

Kovacs, N. (1956). Nature (Lond.), 178, 703.

Liu, P. V., Abe, Y., and Bates, J. L. (1961). J infect. Dis, 108, 218.

Lowbury, E. J. L. (1951). J. clin. Path., 4, 66. (1960). Brit. med J., 1, 994.

- and Collins, A. (1955). J. clin. Path., 8, 47.

Lilly, H. A., and Wilkins, M. (1963). Ibid., 15, 339.

Selenka, F. (1958). Arch. Hyg. (Berl.), 142, 569.

Thornley, M. J. (1960). J. appl. Bact., 23, 37.

Wahba, A. H., and Darrell, J. H. (1965), J. gen. Microbiol, 38, 329.

Wilson, G. S., and Miles, A. A. (1964). Topley and Wilson's Principles of Bacteriology and Immunity, 5th ed., p. 491. Arnold London. 